\title{
EFFECT OF SHORT GLASS FIBER ON MECHANICAL AND RHEOLOGICAL PROPERTIES OF PMMA/SBR VULCANIZATE
}

\author{
G. M. Mamoor, Nida Qamar, Umer Mehmood, M. S. Kamal ${ }^{*}$ \\ Polymer and Process Engineering Department, University of Engineering and Technology, Lahore, Pakistan
}

Received 10 October 2009; received in revised form 30 December 2009

\begin{abstract}
Thermoplastic vulcanizates of polymethyl methacrylate (PMMA) and styrene butadiene rubber (SBR) were prepared by melt processing using dicumyl peroxide (DCP) as a vulcanizing agent. Effect of short glass fiber (SGF) on mechanical and rheological properties of PMMA/SBR vulcanizates has been investigated using universal testing machine and melt flow indexer. The results revealed increase in tensile strength and decrease in melt flow index as well as elongation at break on increasing concentration of short glass fiber. It was also scrutinized that with increase in fiber contents consistency index increases. On increasing fiber contents vulcanizates show more pronounced pseudoplastic behaviour.
\end{abstract}

Keywords: Vulcanizate, Dicumyl peroxide, Cross linking, Short glass fiber, Plastograph

DOI:10.3329/cerb.v13i2.3535

\section{Introduction}

With the emerging trend of replacement of conventional materials with modified polymeric materials in the engineering application, the area of polymer composite research is spreading widely. Settlement of polymers in engineering applications is favored because of their light weight, excellent chemical resistance and outstanding insulation properties [1]. A major hurdle to this attainment is their inclination towards brittle fracture which is a strong function of temperature and strain rate [2].

All glassy polymers are tough up to some extent depending upon the molecular weight provided (typically eight times the molecular weight between the entanglements) and required to form sufficiently strong entangled network, yet they exhibit brittle behavior under certain loading conditions. Brittle thermoplastic such as polystyrene (PS) polymethyl methacrylate (PMMA) show fracture behavior even at low strain under most of the loading conditions [3].

Different techniques are used to minimize the brittle behavior of acrylic polymers by lowering their glass transition temperature. These include: incorporation of conventional plasticizer either before polymerization or by hot mixing, through chemical attachment of functional group of internal plasticizer with the acrylic monomer and addition of rubber in brittle plastic which improves its impact strength [1].

The frequently used method among these three is blending of elastomer with plastic to improve its impact strength and toughness at the cost of modulus.

\footnotetext{
*Corresponding author Email: shaizmalik41@yahoo.com
}

This improvement depends on mechanical properties of plastic and morphological parameters of rubber (particle size, interparticle distance, dispersion of two phases, interfacial adhesion between two phases etc) [4-6]. By reducing the size of elastomer particle phenomenon like cracking and crazing can be minimized efficiently $[6,7]$. Incorporation of rubber to improve impact strength causes a collapse in tensile strength. Fiber fillers are used to enhance mechanical properties especially tensile strength. This improvement of properties depends on certain factors like fiber dispersion, fiber orientation, fiber-matrix adhesion, and fiber length and fiber concentration [8]. No. of studies had been done on thermoplastic elastomers to improve fracture behaviour of polymers $[1-3,5,9,10]$. In present work styrene butadiene rubber toughened PMMA is modified with short glass fiber. Mechanical and rheological properties of PMMA-SBR vulcanizates have been studied for different concentration of short glass fiber.

\section{Experimental}

\subsection{Materials}

Basic materials used in these experiments were PMMA, SBR, SGF and DCP. PMMA (injection grade) CM-207 was imported from Chi Mie Corporation Taiwan. PMMA has a MFI of $8.0 \mathrm{~g} / 10 \mathrm{~min}$ and bulk density of $0.7 \mathrm{~g} / \mathrm{cm}^{3}$. SBR was obtained from Continental Carbon India Limited and short glass fiber was donated by Fiber Craft Industries Lahore. DCP (Dicumyl peroxide $98 \%$ ) used as a vulcanizing agent was taken from Sigma Aldrich Cheme Stelnheim Germany. 


\subsection{Blend Preparation}

Blends were prepared by melt mixing of PMMA, SBR and short glass fiber using DCP as a vulcanizing agent. Mixing was carried out in a Brabender Plasticoder (PLE-330) at temperature of $210^{\circ} \mathrm{C}$ and screw speed of $80 \mathrm{rpm}$. Blends were prepared by adopting following sequence: first of all PMMA was introduced in the plasticoder and allowed to melt completely. SBR was incorporated into the molten PMMA. When the torque became constant, short glass fiber was added. Finally, DCP was added. Mixing time allowed was approximately 5 minutes.

\subsection{Mechanical Testing}

Universal testing machine (Tira Test 2810 Model) was used to measure the tensile strength of the dumbbell shaped specimen according to the ASTM D- 638 at a constant rate $(5 \mathrm{~mm} / \mathrm{min})$ at room temperature of $25^{\circ} \mathrm{C}$. Hydraulic press was used to prepare dumbbell shaped specimen through compression molding at $220^{\circ} \mathrm{C}$.

\subsection{Rheological Testing}

Melt Rheology of the blends was studied by using MFI apparatus (Karg Industritechnik) with die diameter of $2.095 \mathrm{~mm}$ and die length $8 \mathrm{~mm}$, at $200^{\circ} \mathrm{C}$ temperature and under different loads ranging from $15 \mathrm{~kg}$ to $21.6 \mathrm{~kg}$.

\section{Results and Discussion}

\subsection{Plastograph Study}

Processing characteristics of glass reinforced vulcanizates were studied by time-torque graph obtained from plasticoder. After 20 seconds, torque started to increase due to incorporation of PMMA. After reaching the utmost value, torque started to decrease because of melting of PMMA. Addition of SBR into the plasticoder, forces torque to rise for second time. On melting of SBR, torque tends to decrease again. At this stage addition of glass fiber causes the torque to increase. After adding DCP torque rises due to the cross linking of rubber with PMMA. After complete mixing, torque becomes constant.

\subsection{Mechanical Properties}

Tensile strength of PMMA/SBR samples with different concentration of short glass fiber is shown in Figure 1. It is evident from the figure that incorporation of SGF tends to increase tensile strength of vulcanizates. Actually at low fiber concentration, unequal distribution of strain causes the breakage of bond between elastomer and short glass fiber. With increase in fiber concentration stress distributes evenly and fibers give reinforcing effect.

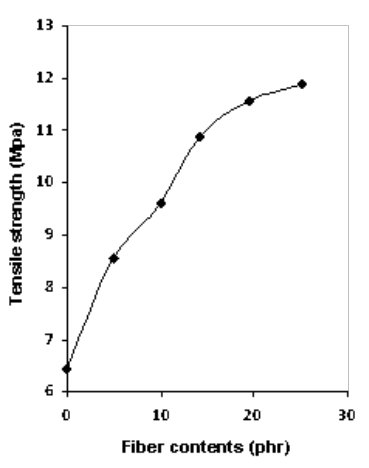

Figure 1: Tensile Strength(Mpa) as a function of fiber contents (phr)

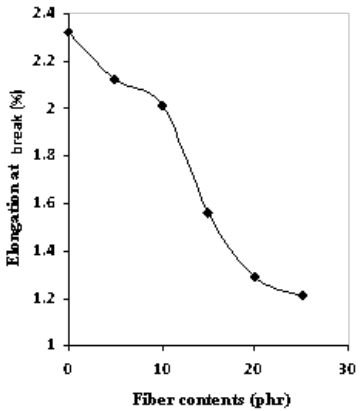

Figure 2: Elongation at break as a function of fiber contents (phr)

Elongation at break for PMMA/SBR samples with varying filler concentration is shown in Figure 2. Elongation at break decreases with increase in fiber contents due to resistance offered by fibers in uncoiling of chains.

\subsection{Rheological Properties}

Rheological measurements are very important for quality control of raw materials, optimization of manufacturing processes and forecasting the performance of a material [11]. Figure 3 shows the relationship between fiber contents and MFI. It is evident from the figure that the melt flow index (MFI) decreases with increase in short glass fiber concentration. Figure also demonstrates that melt flow index is increasing function of load. Melt flow index depends on shape, size, orientation of reinforcing filler, alignment of chains and most importantly on the extent of dispersion of filler in the matrix. As the glass fiber concentration increases dispersion becomes difficult due to agglomerates formation which reduces the flow properties.

Shear stress and strain rate can be calculated by using equation 1 and 2 respectively

$$
\tau=\frac{R_{N} F}{2 \pi R_{P}^{2} L_{N}}
$$




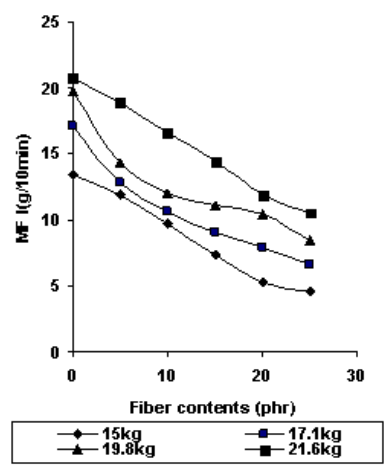

Figure 3: MFI as a function of short glass fiber concentration

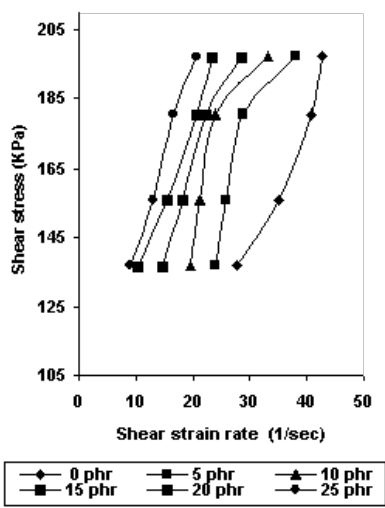

Figure 4: Shear stress $(\mathrm{K} \mathrm{Pa})$ as a function of strain rate $(1 / \mathrm{sec})$

$$
\gamma=\frac{4 Q}{\pi R_{N}^{3}}
$$

where $R_{N}$ is radius of nozzle $(0.105 \mathrm{~cm}), L_{N}$ is nozzle length $(0.8 \mathrm{~cm}), R_{P}$ is piston radius $(0.4737 \mathrm{~cm}), Q$ is flow rate $\left(\mathrm{cm}^{3} / \mathrm{s}\right)$ and $F$ is test load $(\mathrm{kg}) \times 9.087 \times 105$ dyne. Figure 4 clearly indicate behavior of material as pseudoplastic with yield stress. Results also show that at constant strain rate more stress is required for vulcanizates having more fiber contents. Because fibers resist the flow and elongation therefore for constant strain stress requirement is lower for lower fiber contents vulcanizates. Figure 5 demonstrate that power law parameter decreases with increase in fiber contents which implies vulcanizates having larger amount of fiber show more pronounced shear thinning characteristics.

Figure 6 shows relation between fiber contents and consistency index. Consistency index is increasing function of fiber contents. As consistency index is force required to flow a material we can say that more force is required to flow material with increase in fiber contents. This implies that system becomes more viscous with increase in fiber contents which has also been verified from MFI data.

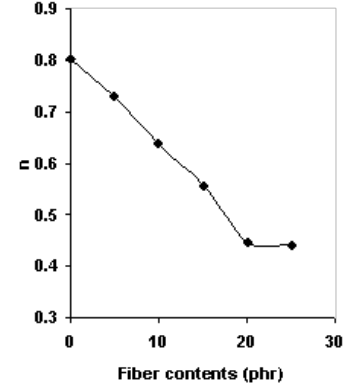

Figure 5: Variation of Power law parameter (n) with fiber contents (phr)

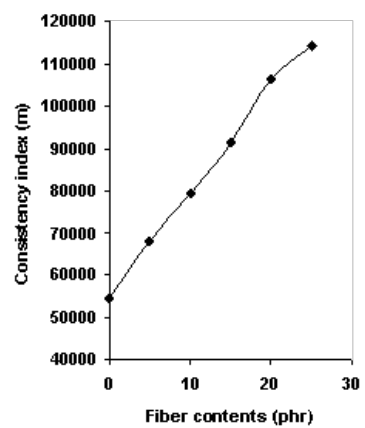

Figure 6: Variation of Consistency index (m) with fiber contents (phr)

Viscosity can be calculated from equation 3

$$
\eta_{a}=m \gamma^{n-1}
$$

where $\eta_{a}$ is the viscosity.

It is clear from Figure 7 that viscosity decreases with increase in strain rate because polymer chains and fibers tend to orient in the flow direction with increase in shear rate. This figure also demonstrates that at constant strain rate viscosity increases with increase in fiber contents because fiber provides resistance to flow. For the case of flow of polymer through circular die, a correction is normally applied to take into account pseudoplastic nature of the melt which implies that the assumed parabolic profile in the die actually illustrates more plug flow behavior [12]. This correction is generally expressed as

$$
\tau_{\text {true }}=\frac{4 Q}{\pi R^{3}} \frac{3 n+1}{4 n}
$$

Curves obtained after applying correction factor are also shown in Figure 8.

\section{Conclusion}

Following results can be concluded from above discussion 


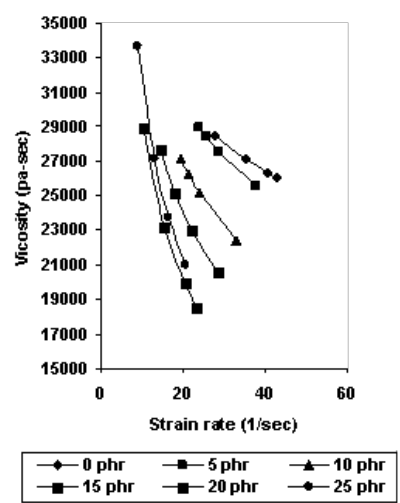

Figure 7: Viscosity (Pa-sec) as a function of strain rate (1/sec)

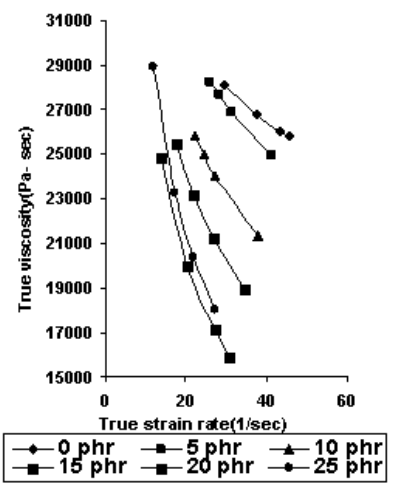

Figure 8: True viscosity (Pa-sec) as a function of true strain rate $(1 / \mathrm{sec})$

- Increase in concentration of short glass fiber causes increase in tensile strength

- Increase in concentration of short glass fiber causes decrease in elongation at break and melt flow index.

- Increase in short glass fiber concentration causes decreases in power law parameter which imply that vulcanizates show more pronounced shear thinning characteristic on adding more SGF.

- Increase in short glass fiber concentration causes increase in consistency index which indicate that vulcanizates become more viscous on addition of SGF.

\section{Acknowledgement}

The authors are thankful to the Department of Polymer And Process Engineering, University Of Engineering and Technology Lahore Pakistan for the Laboratory support.

\section{References}

[1] Andreopoulos A and Papanicolaou G, Rubber-modified polymer composites, Journal of Materials Science, 1987. 22(9):pp. 3417-3420

[2] Belayachi N, Benseddiq N, Nait-Abdelaziz M and Hamdi A, On cavitation and macroscopic behaviour of amorphous polymer-rubber blends, Science and Technology of Advanced Materials, 2008. 9:p. 025008

[3] Van Melick H, Govaert L and Meijer H, On the origin of strain hardening in glassy polymers, Polymer, 2003. 44(8):pp. 24932502

[4] Starke J, Godehardt R, Michler G and BUCKNALL C, Mechanisms of cavitation over a range of temperatures in rubbertoughened PSAN modified with three-stage core-shell particles, Journal of Materials Science, 1997. 32(7):pp. 1855-1860

[5] Zhou C, Si Q, Ao Y, Tan Z, Sun S, Zhang M and Zhang $\mathrm{H}$, Effect of matrix composition on the fracture behavior of rubber-modified PMMA/PVC blends, Polymer Bulletin, 2007. 58(5):pp. 979-988

[6] Parulekar Y and Mohanty A, Biodegradable toughened polymers from renewable resources: blends of polyhydroxybutyrate with epoxidized natural rubber and maleated polybutadiene, Green Chemistry, 2006. 8(2):pp. 206-213

[7] Bucknall C, Karpodinis A and Zhang X, A model for particle cavitation in rubber-toughened plastics, Journal of Materials Science, 1994. 29(13):pp. 3377-3383

[8] Nando G and Gupta B, Short fibre-polymer composites, Ch. Short fibre-thermoplastic elastomer composites, Woodhead Publishing, 1996. pp. 84-115

[9] Da Costa H, Ramos V and Rocha M, Analysis of thermal properties and impact strength of PP/SRT, PP/EPDM and PP/SRT/EPDM mixtures in single screw extruder, Polymer Testing, 2006. 25(4):pp. 498-503

[10] Shah N, Effect of modifier concentration on the fracture behaviour of rubber-modified PMMA, Journal of Materials Science, 1988. 23(10):pp. 3623-3629

[11] Shenoy AV and Saini DR, Thermoplastic melt rheology and processing, CRC Press, 1996

[12] Cogswell FN, Polymer melt rheology: a guide for industrial practice, G. Godwin, 1981 